\title{
Energy Factor Modelling and Model Reference Adaptive Control of Chaos in Boost Converter
}

\author{
http://dx.doi.org/10.3991/ijoe.v8i2.1994 \\ R.Manikumar, R.Kayalvizhi \\ Annamalai University, Annamalai, Tamilnadu, India
}

\begin{abstract}
Chaos is an apparently disordered deterministic behavior, which is universally occurring in many systems in all areas of science. In this paper, chaos in boost converter has been analyzed by taking the load and supply voltage as a bifurcation parameter under open loop condition. The mathematical model of the boost converter is obtained using Energy Factor modeling approach. A Lyapunov's stability based Model Reference Adaptive controller (MRAC) is designed for the boost converter and is implemented to control chaos by keeping the system stable from chaotic stage. The proposed adaptive controller, in the on line mode has the ability to track a specific high-frequency reference voltage and also to adapt for the variations in the load and high-frequency pulsed supply voltage. The simulation results show that the proposed method updates the adjustable parameter values to guarantee stable operation from chaotic stage and also to provide good dynamical responses than the conventional Proportional Integral Derivative (PID) controller.
\end{abstract}

Index Terms-Model Reference Adaptive controller, Pulse width modulator, Direct current, Proportional Integral Derivative, Metal Oxide Semi conductor Field Effect Transistor, Energy Factor.

\section{INTRODUCTION}

The voltage controlled boost converter has a broad range of applications in power control. There are a lot of cases where electrical energy is processed by power electronics before its final consumption. Because of its wide applications the study of the strange phenomenon such as bifurcation and chaos is very essential. The presents of switching elements, nonlinear components (e.g. the power diodes) and control methods (e.g. pulsewidth modulation) implies that circuits are nonlinear, time varying dynamical systems. This paper proposes an adaptive feedback method for controlling chaos in boost converter due to load variations by keeping the system stable from chaotic stage. In practice it is necessary to regulate output voltage against changes in the input voltage and load by adding a feed back control loop.

The circuit diagram of the boost converter is shown in figure.1. The purpose of this paper is to apply MRAC for controlling the Pulse Width Modulator (PWM) of the switching boost converters. In this paper, the chaos of the boost converter operated under open loop is analyzed through bifurcation, by taking the input supply voltage and load as a bifurcation parameter. The mathematical model of boost converter is determined from the Energy Factor (EF) and its relevant parameters.

The MRAC designed by Lyapunov's stability theorem is implemented for controlling the chaos of the Boost converter. The dynamical performance of the proposed method is compared with the PID controller using MATLAB/SIMULINK.
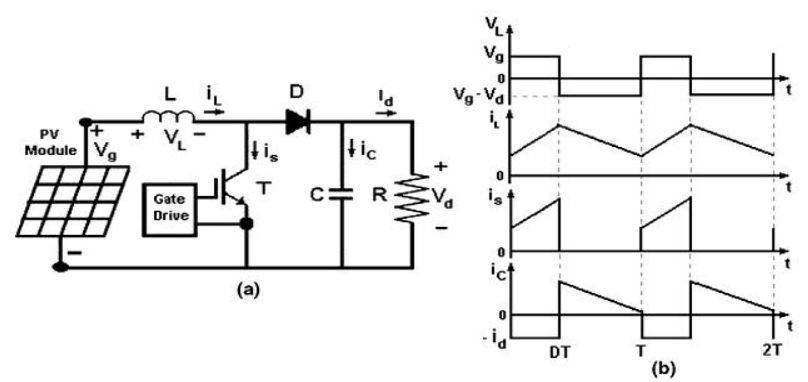

Figure 1. Circuit Diagram of Boost Converter

This paper is organized as follows. Section 2 identifies the occurrence of chaos in Boost converter through bifurcation study under open loop condition. Section 3 provides a description of Energy Factor and Mathematical Modelling of Boost converter. Section 4 details the design and implementation of MRAC using Lyapunov's stability theorem. Section 5 gives the simulation results of the controlled chaos output, phase potrait and comparision of the dynamical responses between the conventional PID and the proposed controller.

\section{BIFURCATION ANALYSIS}

The simulated results for the various load and supply voltage leading to chaos are described in this section. The analysis has done under open loop condition.

The phase portrait (capacitor Voltage Vs inductor current) is taken for various load and supply voltage and it clearly gives the stable and chaotic operation of the boost converter. For certain values of circuit parameters such as line and load variations, a strange phenomenon named chaos is observed. Therefore, a new adaptive control scheme for boost converter is designed to monitor the output loading condition and updates the adjustable parameters and adaptively changes its control parameters to control the chaos as well as to give dynamical performances corresponding to any load and line variations. 


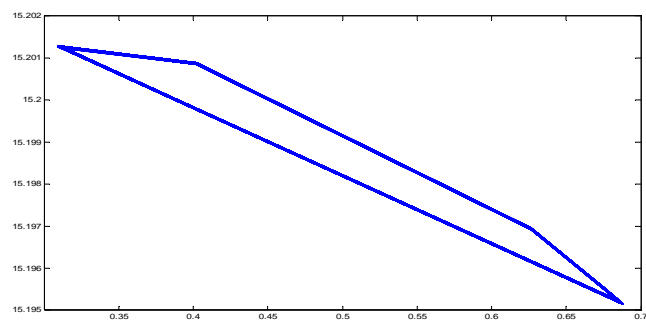

Figure 2. Phase Portrait at load resistance $50 \Omega$

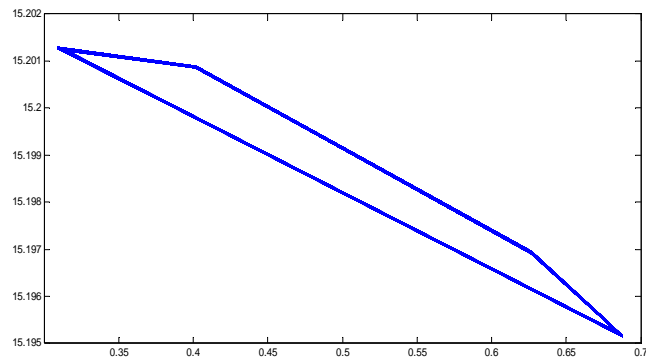

Figure 3. Phase Portrait at load resistance $75 \Omega$

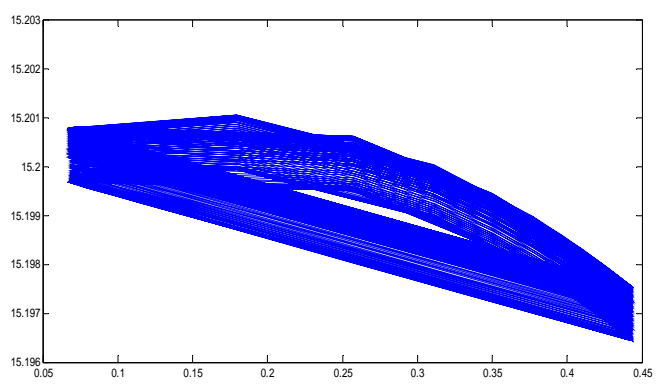

Figure 4. Phase Portrait at load resistance $100 \Omega$

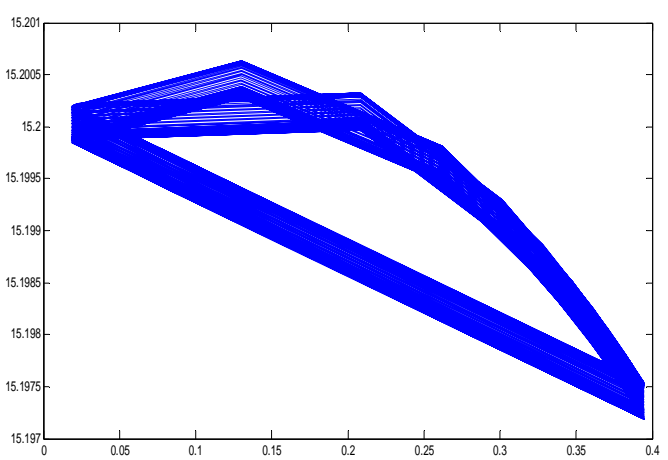

Figure 5. Phase Portrait at load resistance $125 \Omega$

TABLE I.

\begin{tabular}{|c|c|}
\hline Load Resistance $(\boldsymbol{\Omega})$ & Operation \\
\hline $50 \Omega$ & stable \\
\hline $75 \Omega$ & stable \\
\hline $100 \Omega$ & chaos \\
\hline $125 \Omega$ & chaos \\
\hline
\end{tabular}

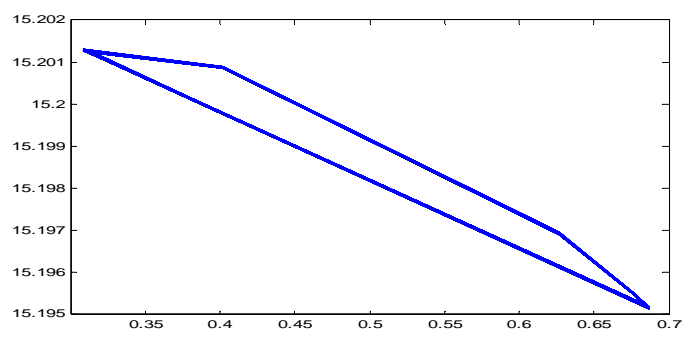

Figure 6. Phase Portrait at supply voltage 10V

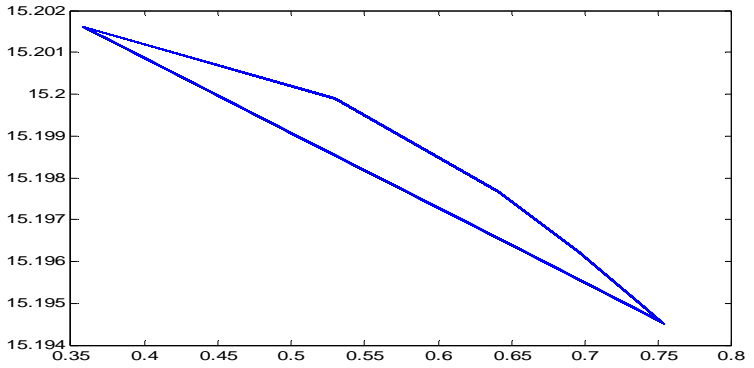

Figure 7. Phase Portrait at supply voltage 9V

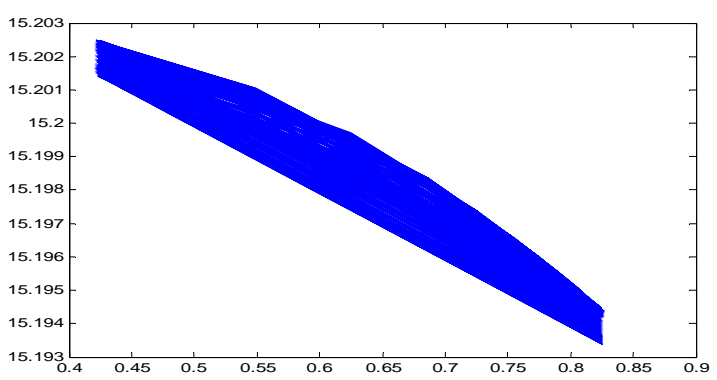

Figure 8. Phase Portrait at supply voltage 8V

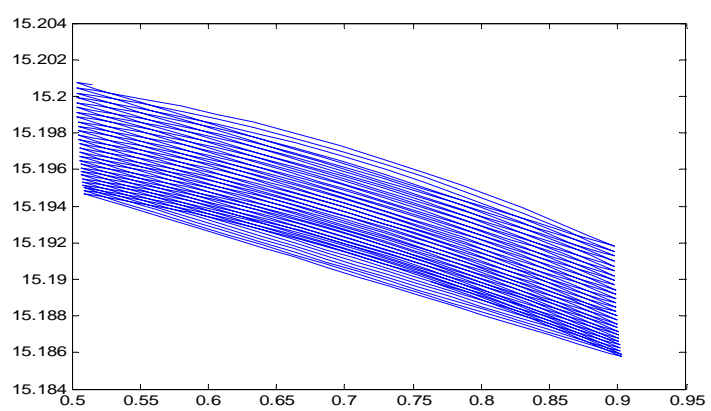

Figure 9. Phase Portrait at supply voltage 7V

TABLE II.

\begin{tabular}{|c|c|}
\hline Supply Voltage (V) & Operation \\
\hline $10 \mathrm{~V}$ & stable \\
\hline $9 \mathrm{~V}$ & stable \\
\hline $8 \mathrm{~V}$ & chaos \\
\hline $7 \mathrm{~V}$ & chaos \\
\hline
\end{tabular}




\section{ENERGY FACTOR AND MATHEMATICAL MODELLING}

All power DC/DC converters have a pumping circuit to transfer the energy from source to some passive energy storage elements, e.g, inductors and capacitors. The Energy Factor (EF) and its associated parameters comprising the pumping energy (PE), stored energy (SE), capacitor/inductor stored energy ratio (CIR) and energy losses (EL), can illustrate the unit step response which may be helpful for system deign and in anticipating DC/DC converter characteristics. The DC/DC Boost converters are analyzed to demonstrate the application of $\mathrm{EF}, \mathrm{PE}, \mathrm{SE}$ and CIR. The input voltage and current are defined as $V_{1}$ and $I_{1}$ respectively, and the output voltage and current are defined as $V_{2}$ and $I_{2}$ respectively. The switching frequency, switching time period and duty cycle ratios are defined as $\mathrm{f}, \mathrm{T}$ and $\mathrm{k}$ respectively.

The energy quantization is measured by the PE, which is used to count the input energy in the switching period $\left(\mathrm{V}_{1}\right.$ is usually constant). Its calculation formula is

$$
\mathrm{PE}=\mathrm{V}_{1} \mathrm{I}_{1} \mathrm{~T}
$$

The stored energy in an inductor is $\mathrm{W}_{\mathrm{L}}=\frac{1}{2} \mathrm{~L} \mathrm{I}_{\mathrm{L}}{ }^{2}$

The stored energy across a capacitor is $\mathrm{W}_{\mathrm{C}}=\frac{1}{2} \mathrm{C} \mathrm{V}_{\mathrm{C}}^{2}$

Therefore, if there are $\mathrm{n}_{\mathrm{L}}$ inductors and $\mathrm{n}_{\mathrm{C}}$ capacitors, the total stored energy in a DC/DC converter is

$$
\mathrm{SE}=\sum_{j=1}^{n_{L}} W_{L j}+\sum_{j=1}^{n_{C}} W_{c j}
$$

The capacitor/inductor stored energy ratio (CIR) is

$$
\mathrm{CIR}=\frac{\sum_{j=1}^{\pi} W_{C j}}{\sum_{j=1}^{\pi L} W_{L j}}
$$

Another factor is the EL in period T, which are proportional to the power losses.

$$
\mathrm{EL}=\mathrm{P}_{\text {loss }} * \mathrm{~T}
$$

The Energy Factor is the ratio of stored energy and

$$
\text { pumping energy. Therefore, } \mathrm{EF}=\frac{\mathrm{SE}}{\mathrm{PE}}
$$

The EF is used to describe the characteristics of power DC/DC converters. Usually, most DC/DC converter analysis assumes that input power is equal to output power, $P_{\text {in }}=P_{o}$ (or $\left.V_{1} I_{1}=V_{2} I_{2}\right)$, so that pumping energy is equal to output energy in a period: $P E=V_{1} I_{1} T=V_{2} I_{2} T$. It corresponds that the efficiency $(\eta)=V_{2} I_{2} T / P$.E. If the load is purely resistive (R), $V_{2}=I_{2} R$, and the Voltage transfer gain (M) of DC/DC converter is $\mathrm{M}=\left(\mathrm{V}_{2} / \mathrm{V}_{1}\right)=$ $\left(\mathrm{I}_{2} \mathrm{R} / \mathrm{V}_{1}\right)$.

And,

$$
\begin{aligned}
& P_{\text {in }}=P_{o}+P_{\text {loss }} \\
& \text { The power transfer efficiency is } \eta=\frac{P o}{P i n}
\end{aligned}
$$

The time constant of DC/DC converter is defined as

$$
\tau=\frac{2 \mathrm{~T}^{*} \mathrm{EF}}{1+\mathrm{CIR}}\left(1+\mathrm{CIR} \frac{1-\eta}{\eta}\right)
$$

The time constant $\tau$ is used to estimate the converter transient operation. It is proportional to the process settling time.

Since a converter usually consist of multiple passive energy storage elements, for this investigation, the converter response should usually involve an oscillation component.

The damping time constant $\tau_{\mathrm{d}}$ of DC/DC converter is defined as

$$
\tau_{\mathrm{d}}=\frac{2 \mathrm{~T} * \mathrm{EF}}{1+\mathrm{CIR} \eta} \frac{\mathrm{CIR}}{\eta+\operatorname{CIR}(1-\eta)}
$$

$\tau_{\mathrm{d}}$ is used to estimate the converter response with oscillation. Both $\tau$ and $\tau_{\mathrm{d}}$ are independent from the switching frequency $\mathrm{f}$ and conduction duty cycle ratio $\mathrm{k}$ and also available to form the transfer function of the $\mathrm{DC} / \mathrm{DC}$ converter in S-domain.

The transfer function of the DC/DC converter can be written in mathematical model as

$$
\mathrm{G}(\mathrm{S})=\frac{\mathrm{M}}{1+\mathrm{s} \tau+\mathrm{s}^{2} \tau \tau_{d}}
$$

The transfer function of the DC/DC converter can be approximated as mathematical model in first order form as

$$
\mathrm{G}(\mathrm{S})=\frac{\mathrm{M}}{1+\mathrm{S} \tau}
$$

To verify the theoretical analysis and the design of previous section, the parameters and specifications of $\mathrm{DC} / \mathrm{DC}$ boost converter are taken and are shown in table III.

TABLE III.

SPECIFICATIONS AND PARAMETERS OF BOOST CONVERTER

\begin{tabular}{|c|c|c|c|}
\hline Specification & value & $\begin{array}{c}\text { Circuit } \\
\text { Parameters }\end{array}$ & Value \\
\hline Input Voltage & $10 \mathrm{~V}$ & Inductor, $\mathrm{L} 1$ & $100 \mu \mathrm{H}$ \\
\hline Output Voltage & $16 \mathrm{~V}$ & Capacitor, $\mathrm{C} 1$ & $200 \mu \mathrm{F}$ \\
\hline
\end{tabular}

When the converter changes from one steady state to another, the corresponding stored energy changes. Therefore, there must be a transient process from one steady state to the new steady state. The Energy Factor, its relevant application parameters, voltage transfer gain (M) and time constant $(\tau)$ of boost converter are determined at the operating voltage $16 \mathrm{~V}$ and for the switching frequency $100 \mathrm{kHz}$ and the values are listed in table IV. 
TABLE IV.

ENERGY FACTOR, RELEVANT PARAMETERS, VOLTAGE TRANSFER GAIN AND TIME CONSTANT OF CUK CONVERTER

\begin{tabular}{|l|c|}
\hline Pumping Energy, PE & $6.949 \mathrm{e}-5$ \\
\hline Stored Energy, SE & 0.006625 \\
\hline Capacitor/Inductor stored Energy, CIR & 273.4 \\
\hline Energy Losses, EL & 0.002548 \\
\hline Energy Factor, EF & 95.33 \\
\hline Power Efficiency, $\boldsymbol{\eta}$ & 0.7599 \\
\hline Voltage transfer gain, $\mathbf{M}$ & 1.013 \\
\hline Time constant, $\boldsymbol{\tau}$ & 0.0006087 \\
\hline
\end{tabular}

The transfer function of the CUK converter in Sdomain is found to be

$$
\mathrm{G}(\mathrm{S})=\frac{1.013}{1+0.0006087 \mathrm{~s}}
$$

From the above obtained transfer function model, the controller tunings for the PID controller using synthesis method are found to be $\mathrm{Kp}=1.987, \mathrm{Ki}=3265$ and $\mathrm{Kd}=0$.

Finally, based on Lyapunov's stability theorem, the proposed controller containing adjustable parameters are implemented for boost converter by choosing adaptation gain, $\gamma=0.7$. This proposed controller guarantees closedloop system stability and a tracking performance for the output voltage for the variations in the line voltage, reference voltage and the load.

\section{Sytematic Controller Design}

This section constructs a Lyapunov's stability based MRAC for controlling the PWM width of Boost converter. The MRAS control system for Boost converter is shown in figure. 10 .

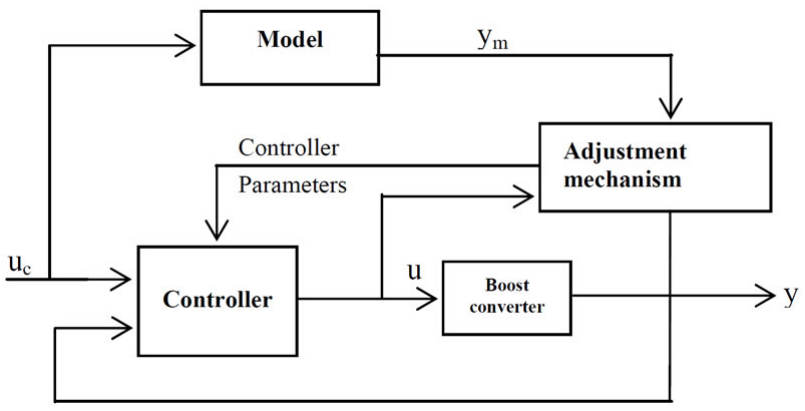

Figure 10. Block Diagram of MRAC

For time-varying systems, the following stability theorem can now be stated. Let $\mathrm{x}=0$ be an equilibrium point for the time-variable differential function of the type

$$
\frac{\mathrm{dx}}{\mathrm{dt}}=f(\mathrm{x}, \mathrm{t}) \text { and } \mathrm{D}=\left\{\mathrm{x} \in \mathrm{R}^{\mathrm{n}} \mid\|\mathrm{x}\|<\mathrm{r}\right\}
$$

Let $\mathrm{V}$ be a continuously differential function such that

$$
\alpha_{1}(\|\mathrm{x}\|) \leq \mathrm{V}(\mathrm{x}, \mathrm{t}) \leq \alpha_{2}(\|\mathrm{x}\|)
$$

$\frac{\mathrm{dv}}{\mathrm{dt}}=\frac{\partial \mathrm{v}}{\partial \mathrm{t}}+\frac{\partial \mathrm{v}}{\partial \mathrm{x}}+f(\mathrm{x}, \mathrm{t}) \leq-\alpha_{3}(\|\mathrm{x}\|)$ For $\forall \mathrm{t} \geq 0$, where $\alpha_{1}, \alpha_{2}$ and $\alpha_{3}$ are class $\mathrm{k}$ functions. Then $\mathrm{x}=0$ is uniformly asymptotically stable.

While using Lyapunov theory for adaptive system, $\frac{\mathrm{dv}}{\mathrm{dt}}$ is usually negative semi definite where $\mathrm{V}$ is a Lyapunov function. The procedure is to determine the error equation and a Lyapunov function with a bounded second derivative.

For a first order system, the system is described by the plant as $\quad \frac{d y}{d t}=-a y+b u$; Where ' $u$ ' is the control variable (i.e., the plant input), ' $y$ ' is the measured output (i.e., the plant output), ' $a$ ' and ' $b$ ' are the plant parameters. The desired response is given by the equation

$$
\frac{d y_{m}}{d t}=-a_{m} y_{m}+b_{m} u_{c}
$$

Where ' $u_{c}$ ' is the model input, ' $y_{m}$ ' is the model output, ' $a_{m}$ ' and ' $b_{\mathrm{m}}$ ' are the model parameters. Let the controller be $u(t)$ $=\theta_{1} \mathrm{u}_{\mathrm{c}}(\mathrm{t})-\theta_{2} \mathrm{y}(\mathrm{t})$. The controller has two parameters $\theta_{1}$ and $\theta_{2 .}$ If they are chosen to be $\theta_{1}=\theta_{1}^{0}=\frac{\mathrm{b}_{\mathrm{m}}}{\mathrm{b}}$;

$$
\theta_{2}=\theta_{2}^{0}=\frac{\mathrm{a}_{\mathrm{m}}-\mathrm{a}}{\mathrm{b}}
$$

The input-output relations of the system and model are the same. This is called perfect model following. To apply Lyapunov stability theory, introduce the error as $\mathrm{e}=\mathrm{y}-\mathrm{y}_{\mathrm{m}}$

Since, To make the error small, it is natural to derive a differential equation for error.

$$
\frac{\mathrm{de}}{\mathrm{dt}}=-\mathrm{a}_{\mathrm{m}} \mathrm{e}-\left(\mathrm{b} \theta_{2}-\mathrm{a}_{\mathrm{m}}+\mathrm{a}\right) \mathrm{y}+\left(\mathrm{b} \theta_{1}-\mathrm{b}_{\mathrm{m}}\right) \mathrm{u}_{\mathrm{c}}
$$

It is now to construct a parameter adjustment mechanism that will derive the parameters $\theta_{1}$ and $\theta_{2}$ to their desired values. For this purpose, assume $b \gamma>0$ and introduce the following quadratic function. $\mathrm{V}\left(\mathrm{e}, \theta_{1}, \theta_{2}\right)=$ $\frac{1}{2}\left(e^{2}+\frac{1}{b \gamma}\left(b \theta_{2}+a-a_{m}\right)^{2}+\frac{1}{b \gamma}\left(b \theta_{1}-b_{m}\right)^{2}\right) \mathrm{Wh}$ ere ' $\gamma$ ' is adaptation gain. This function is zero when e is zero and the controller parameters are equal to the correct values.

For the function to qualify as a Lyapunov function, the derivative $\frac{\mathrm{dv}}{\mathrm{dt}}$ must be negative. The derivative

$$
\frac{d v}{d t}=\frac{1}{2}\left(2 e \frac{d e}{d t}+\frac{1}{b y} 2\left(b \theta_{2}+a-a_{m}\right) \cdot b \cdot \frac{d \theta_{2}}{d t}+\frac{1}{b y} 2\left(b \theta_{1}-b_{m}\right) \cdot b \cdot \frac{d \theta_{1}}{d t}\right)_{T}
$$
he condition is that $\frac{\mathrm{dv}}{\mathrm{dt}}$ should be negative semi-definite. If the parameters are updated as

$$
\frac{\mathrm{d} \theta_{1}}{\mathrm{dt}}=-\gamma \mathrm{u}_{\mathrm{c}} \mathrm{e} \text { and } \frac{d \theta_{2}}{d t}=\gamma y e, \text { then }
$$




$$
\frac{\mathrm{dv}}{\mathrm{dt}}=-\mathrm{a}_{\mathrm{m}} \mathrm{e}^{2}
$$

The derivative of $\mathrm{V}$ with respect to time is thus negative semi definite but not negative definite. This implies that $\mathrm{v}(\mathrm{t}) \leq \mathrm{v}(0)$ and thus that e, $\theta_{1}$ and $\theta_{2}$ must be bounded. This implies that $\mathrm{y}=\mathrm{e}+\mathrm{y}_{\mathrm{m}}$ also is bounded.

\section{Simulated Result of Controlled ChaOs OUTPUT}

Simulations have been carried out to verify the chaos controlling idea. The chaos coming due to the load variation is successfully controlled. The Time domain waveform (output voltage Vs time) when load resistance changes from $50 \Omega$ to $125 \Omega$ is shown for open loop, PID controller and proposed controller respectively. Also, the corresponding phase portrait (capacitor voltage Vs inductor current) of the proposed controller given below shows the stable result.

The regulatory response (output voltage Vs time) of the PID controller and proposed controller are given below. The proposed scheme provides good dynamical response, guarantees closed loop system stability and tracking performance for even when the supply voltage drops from $10 \mathrm{~V}$ to $8 \mathrm{~V}$ for the operating voltage $16 \mathrm{~V}$.

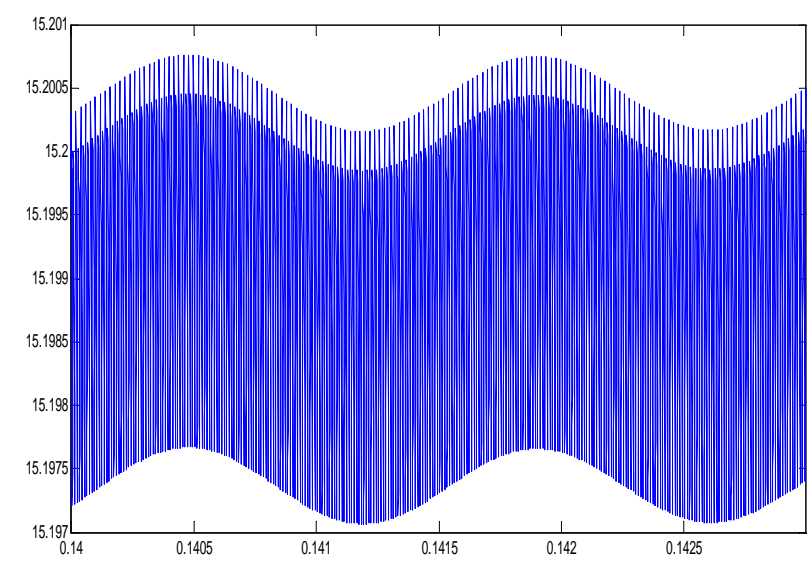

Figure 11. Time domain waveform for open loop

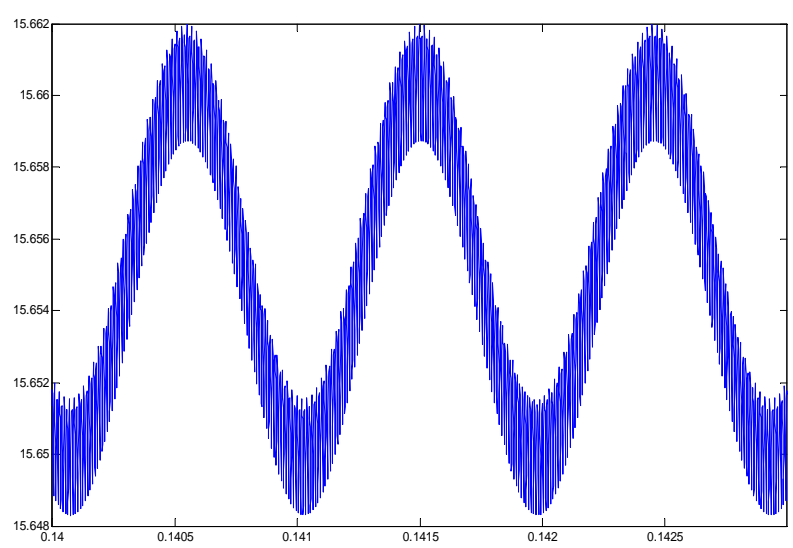

Figure 12. Time domain waveform for PID coctroller

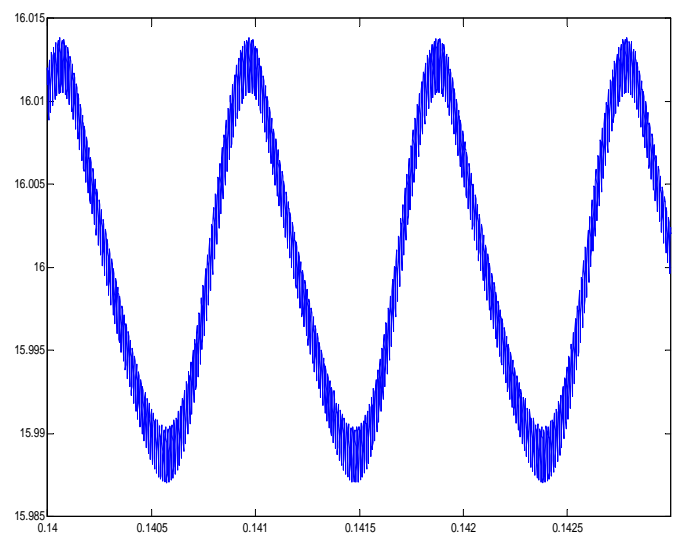

Figure 13. Time domain waveform for proposed controller

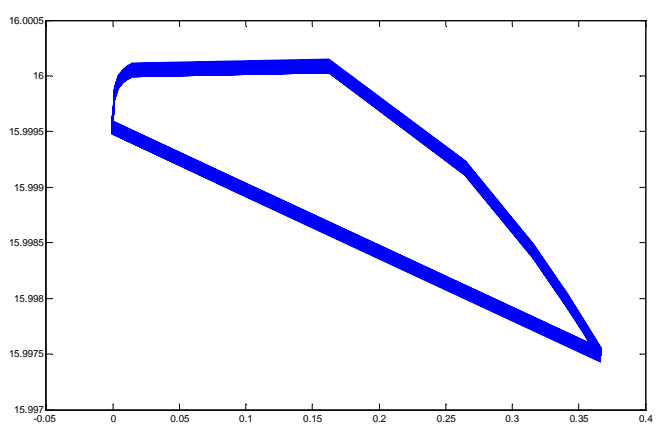

Figure 14. Phase Portrait for proposed controller

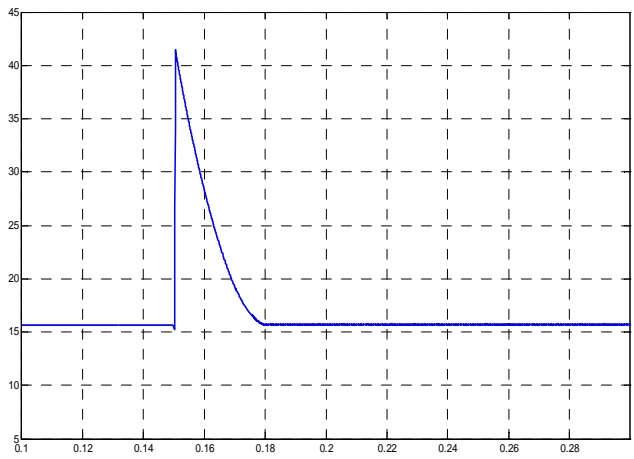

Figure 15. Regulatory Response of PID controller

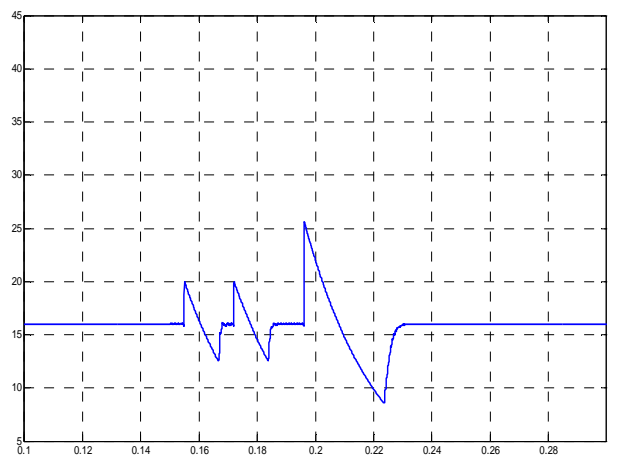

Figure 16. Regulatory Response of Proposed controller 


\section{CONCLUSIONS}

The voltage controlled boost converter is taken for the analysis of bifurcation and chaos. The simulated result have been shown for various load and line voltages. And, the stages leading to chaos are observed for boost converter. To control such spurious effects in voltage controlled boost converter, an adaptive method through energy factor modeling has been considered. It is proved that stable operation is possible and chaos has been controlled by keeping the system stable from chaotic stage.

\section{ACKNOWLEDGMENTS}

The authors would like to acknowledge Dr. S. P. Natarajan, Department of Electronics and Instrumentation Engineering, Annamalai University, Annamalai Nagar for granted permission to use the power electronics laboratory.

\section{REFERENCES}

[1] S.Sruthi, A.Kavitha and G.Uma "control of Chaos in Buck converter using Adaptive Feedback Sliding Mode Control scheme", computational Intelligence in Power Apparatus and Systems (CIPS 2008)

[2] F.L.Luo and H.Ye "Energy factor and mathematical modelling for power DC/DC converters”, IEEE proc., Electr. Power Appl., 2005.

[3] Banerrjee.S and G.C. Verghese , H. "Nonlinear phenomena in Power Electronics”, IEEE Press. Autom control, 2001.

[4] David C. Hamil and David J. Jeffries, "Sub harmonics and chaos in a controlled switched-mode power converter". IEEE Transaction on circuits and systems, Vol. 35, N0.8, July 1988

[5] Arbetter,.B and Maksimovic, "Feedforward Pulse Widh Modulator for Switching Power Converters" IEEE Transactions on Power Electronics, Vol. 9, No.2, March, 1997.

[6] Sira-Rameirez, H. "A geometric approach to pulse-width modulated control in nonlinear dynamical systems”, IEEE Trans. Autom control,1989.
[7] De Keyser, R.M.C “A gentle Introduction to Model Based Predictive control” Europen Union EC-ALFA-PADI 2 Int. Conference on Control Engineering and Signal Processing, Piura, 1998.

[8] Sasaki.s and T.Inoue "Systematic approach to robust nonlinear voltage control of buck/boost converter" In: Proc. $31^{\text {st }}$ IEEE Power Electronics Specialists conference 2000.

[9] Karl Johan Astorm, Bjorn Wittenmark, Adaptive control Second edition, Lund Institute of Technology, Pearson Education. 2006.

[10] E.Ott. C.Greobogi and J.A Yoke, "Controlling chaos", Phsy.Rev.Lett, Vol 64.pp,1196-1199,1990.

[11] George Stephanopoulos Chemical process control, An introduction to theory and practice ,Prentice-hall India publications, 2000.

\section{AUTHORS}

R. Manikumar obtained his B.E degree in Electronics and Instrumentation Engineering in the year 2001 and received M.E. degree in Process Control and Instrumentation Engineering in 2005 from the Annamalai university, Chidambaram. Presently he is working as a a assistant professor in the Department of Instrumentation Engineering, Annamalai University. His areas of research are Process Control and Power electronics.

Dr. R. Kayalvizhi obtained her B.E degree in Electronics and Instrumentation Engineering in the year 1984 and further the M.E. degree in Power Systems in the year 1990 from the Annamalai University, Chidambaram. . Presently, she is working as a Professor in the Department of Instrumentation Engineering, Annamalai University. She is guiding many $\mathrm{Ph} . \mathrm{D}$ research scholars in the areas like Power converters, Neural Networks and Fuzzy Logic applied to Power Electronics Control, Image processing and non linear dynamics and control of chaos in power electronic conveters. She published many international and national journals.

Received 23 February 2012. Published as resubmitted by the authors 27 April 2012. 